\title{
Childhood Characteristics of Adolescent Inpatients with Early-Onset and Adolescent-Onset Disruptive Behavior
}

\author{
Sjoukje B. B. de Boer - Floortje V. A. van Oort • \\ Marianne C. H. Donker • Fop Verheij • Albert E. Boon
}

Published online: 30 March 2012

(C) The Author(s) 2012. This article is published with open access at Springerlink.com

\begin{abstract}
Childhood characteristics are associated with lifecourse-persistent antisocial behavior in epidemiological studies in general population samples. The present study examines this association in an inpatient sample. The purpose is to identify easily measurable childhood characteristics that may guide choice of treatment for adolescent psychiatric inpatients with severe disruptive behavior. Patients $(N=203)$ were divided into two groups with either early-onset (EO) or adolescent-onset (AO) disruptive behavior, based on ages at which professional care was used for disruptive behavior, referral to special education, and criminal offences. Both groups differed on several childhood characteristics. No gender differences in these characteristics were found. Logistic regression analysis indicated that individuals with grade retention in primary school, childhood
\end{abstract}

S. B. B. de Boer $(\square) \cdot$ A. E. Boon

De Fjord, Centre of Orthopsychiatry

and Forensic Youth Psychiatry,

Poortmolen 121

2906 RN Capelle aan den IJssel, The Netherlands

e-mail: s.deboer@lucertis.nl

F. V. A. van Oort $\cdot$ F. Verheij

Erasmus MC-Sophia (Sophia Children's Hospital),

Erasmus MC University Medical Center,

Rotterdam, The Netherlands

M. C. H. Donker

Ministry of Health, Welfare and Sports,

The Hague, The Netherlands

S. B. B. de Boer • A. E. Boon

De Jutters, Centre of Youth Mental Healthcare Haaglanden,

The Hague, The Netherlands

M. C. H. Donker

Erasmus MC University Medical Center,

Rotterdam, The Netherlands impulsive behavior, and a history of physical abuse, had the highest probability of being member of the EO group. These characteristics are reasonably easy to identify, likely apply to other clinical samples as well, and may help clinicians to target their treatment.

Keywords Adolescents · Antisocial behavior - Psychiatric inpatients $\cdot$ Childhood characteristics

\section{Introduction}

In epidemiological research, Moffitt (1993) found that a relatively small proportion of the population engaged in antisocial behavior at a very young age. In about a quarter (Veenstra et al. 2009) to half (Moffitt et al. 1996) of these children this disruptive behavior was limited to childhood, the remainder of this group were labeled life-coursepersistent (LCP), because of the continuous course of their antisocial behavior. A larger group was found to be involved in antisocial behavior only during adolescence, therefore their behavior was labeled adolescence-limited (AL). Although during adolescence these groups do not differ in frequency and seriousness of offending, it is argued that they differ in etiology, prognosis and classification of their behavior as either normative or pathological (Moffitt 1993, 2003; Moffitt et al. 2002, 2008).

This paper tests the classification of these two hypothetical prototypes in an inpatient sample of youths who had severe disruptive behavior combined with psychiatric disorders. Disruptive behavior includes aggression, oppositional behavior, status offences (e.g. running away, truancy, substance abuse), and property violations (e.g. lying or deceiving, selling drugs, vandalism). Replication of findings from general population studies in clinical populations is 
important, because findings then become clinically useful (Moffitt et al. 2008). In clinical populations it is often difficult to classify adolescents as having LCP or AL disruptive behavior, as information of childhood disruptive behavior is not always present, or difficult to collect retrospectively. As persistence of the behavior is even more difficult to determine retrospectively, and it is unclear whether disruptive behavior in adolescence will persist in later life we choose to use the terms early-onset (EO) and adolescent-onset (AO). Adolescents with severe disruptive behavior who also had disruptive behavior in childhood, we label as EO; adolescents in this group have a significant chance to further develop as those in Moffitt's LCP group. The group of adolescents who did not have disruptive behaviors in childhood, we label as $\mathrm{AO}$; adolescents in this group will presumably develop as those in Moffitt's AL group.

A set of risk indicators that is relatively easy to collect, or that is already collected in clinical process, and is strongly predictive of EO versus $\mathrm{AO}$ disruptive behavior, helps the clinician to assess the likelihood that an adolescent belongs to the LCP or the AL group. This may be of importance for choices with regard to treatment. Moffitt argued that both groups need intervention, but that they require different intervention goals and approaches (Moffitt et al. 2008). The causes of LCP antisocial behavior may be completely different from the causes of $\mathrm{AL}$ antisocial behavior, but beyond that the personal, educational and social development of the LCP group may have been seriously hampered by the sheer duration of their problems. The main goal of this study is to identify factors that diagnosticians can use to differentiate between the subtypes LCP and AL disruptive behavior in a clinical setting. According to Moffitt (1993), the strongest predictors of LCP antisocial behavior were individual and family characteristics. It is expected that this will also be so for EO disruptive behavior. Individual factors include under-controlled temperament (Aguilar et al. 2000; Moffitt 2003; Moffitt and Caspi 2001; Moffitt et al. 1994), neurological abnormalities and delayed motor development (Moffitt 1993), low intellectual ability (Fergusson et al. 2000; Moffitt 2003; Moffitt and Caspi 2001; Moffitt et al. 1994; Nagin and Farrington 1992; Odgers et al. 2008), reading difficulties (Moffitt 2003; Moffitt and Caspi 2001; Moffitt et al. 1994; Odgers et al. 2008), low school achievement (Chung et al. 2002; Moffitt 1993; Vaughn et al. 2011), poor scores on neuropsychological tests, caused by birth complications for example (Moffitt 2003; Moffitt and Caspi 2001; Moffitt et al. 1994; Tibbetts and Piquero 1999), hyperactivity and/or attention problems (Fergusson et al. 2000; Moffitt and Caspi 2001; Moffitt et al. 1994; Nagin and Tremblay 2001; Odgers et al. 2008; Wiesner and Capaldi 2003), low heart rate (Moffitt 2003; Moffitt and Caspi 2001; Moffitt et al. 1994; Odgers et al. 2008), psychopathic personality traits, violent behavior (Moffitt and Caspi 2001; Moffitt et al. 2002, 1994), and broad psychiatric comorbidity (Vaughn et al. 2011).

Family and context factors associated with LCP antisocial behavior include: having a teenage single parent (Fergusson et al. 2000; Moffitt and Caspi 2001; Nagin and Tremblay 2001), having a single parent at birth (Aguilar et al. 2000; Fergusson et al. 2000; Kjelsberg 1999; Tibbetts and Piquero 1999), maltreatment (mothers who were harsh or neglectful, harsh or inconsistent discipline, physical abuse, sexual abuse, child abuse) (Aguilar et al. 2000; Dean et al. 1996; Moffitt and Caspi 2001; Odgers et al. 2008; Patterson et al. 1998; Wiesner and Capaldi 2003), much family conflict (Fergusson et al. 2000; Moffitt and Caspi 2001; Odgers et al. 2008), inadequate parenting (low parental supervision, inconsistent discipline)(Chung et al. 2002; Moffitt and Caspi 2001; Moffitt et al. 2002; Nagin and Farrington 1992; Odgers et al. 2008; Patterson et al. 1998; Wiesner and Capaldi 2003), many changes of primary care taker (Kjelsberg 1999; Moffitt and Caspi 2001; Nagin and Farrington 1992; Patterson et al. 1998; Tibbetts and Piquero 1999), and sibling deviance (Moffitt 1993).

Parental characteristics associated with LCP antisocial behavior were: mothers with poor mental health (Moffitt and Caspi 2001; Odgers et al. 2008; Shaw et al. 1996), parental criminal conviction (Fergusson et al. 2000; Kjelsberg 1999; associated with AL: Nagin and Farrington 1992; Odgers et al. 2008), parental deviance (Moffitt 1993), parental alcoholism, alcohol problems or illicit drug use (Fergusson et al. 2000), low educational attainment or IQ of the mother (Fergusson et al. 2000; Nagin and Tremblay 2001; Odgers et al. 2008), and low family socio-economic status (SES) (Fergusson et al. 2000; Fontaine et al. 2009; Kjelsberg 1999; Moffitt and Caspi 2001; Odgers et al. 2008; Patterson et al. 1998; Tibbetts and Piquero 1999).

Individuals on the $\mathrm{AL}$ path tended to have backgrounds that were normative (Moffitt and Caspi 2001). AL offending was assumed to be most strongly related to associations with deviant peers. Attitudes toward adulthood and autonomy, cultural and historical context and age were considered the strongest predictors of short-term offending (Moffitt 1993).

Thus far, the distinction in $\mathrm{EO}$ and $\mathrm{AO}$ antisocial behavior has hardly been made in clinical practice. We expect that both groups are represented in our sample and that factors that were found to associate with LCP antisocial behavior in epidemiological studies are also associated with EO disruptive behavior in a clinical sample. The purpose of the present study is to find individual, parental, and family and context risk factors that were present in childhood, that are relatively easy to collect, and are strongly predictive of EO versus AO disruptive behavior in a clinical sample of adolescents with severe disruptive behavior. 


\section{Method}

Setting

The present study was conducted at De Fjord, an orthopsychiatric and forensic youth treatment facility in Rotterdam, The Netherlands. In The Netherlands, the term orthopsychiatry entails specialized treatment of youngsters diagnosed with severe disruptive behavior (that may or may not include offending) in combination with one or more psychiatric disorders. The Fjord offers outpatient and day treatment, and a specialized residential treatment program. Patients are eligible for treatment if they are referred by other specialized youth care institutions, i.e. institutions that are predominantly focused on developmental, psychiatric or criminal problems in children and adolescents. In addition to referral, patients must meet the following inclusion criteria: age between 16 and 20 years, presence of severe behavioral as well as psychiatric problems, and (a history of) previous treatment. These criteria result in a patient sample with severe and complex problems that were not resolved by treatments elsewhere. Patients functioning below borderline intellectual level (IQ <70), with predominant addiction problems, or with severe recidivist criminal conduct for which specialized, individual forensic treatment is indicated, are not eligible for treatment.

\section{Procedure}

All patients admitted between 1995 and 2008 were included in the study. After a verbal description of the study to the subjects, written informed consent was obtained. All patients $(N=223)$ agreed to participate. When patients were under age 16, in accordance with the statutory requirement in the Netherlands, informed consent was also obtained from the parents. The statistical analyses in present study were performed for 203 patients for whom the age of onset was determined $(91.0 \%$ of the sample).

Disruptive behavior during childhood, its age of onset, and other childhood characteristics were obtained by using multi-informant (adolescent, parent and therapist), multimethod (self-report, interview, records from mental health care institutions where patients had previously been treated) information. The adolescent was interviewed by the researcher, and the therapist reported all known characteristics of the youngster via a questionnaire. This information was partly based on information reported by parents and/or referring professional (e.g. guardian or probation officer) during the intake procedure. Information from records was obtained by the researcher. A behavior or characteristic was considered present when mentioned by at least one of the sources, and absent when not present according to all sources. When information was not available, it was coded unclear (or missing, depending on the reason for unavailability). Some characteristics were considered too aggravating to be asked directly by the researcher (e.g. sexual abuse, physical abuse), and were therefore obtained from the therapist (i.e. via the therapist who asked the adolescent) and from records.

\section{Measures}

Presence of disruptive behavior during childhood was determined, based on the age at which help was sought because of disruptive behavior, special education was indicated due to disruptive behavior, and the age at which the youngster started to commit criminal offences. For each individual the presence and age of onset of disruptive behaviors was determined. For age of onset the earliest age reported by any of the sources was used. Disruptive behavior included aggression (overt, destructive: e.g. physical abuse, sexual offences, threatening someone), oppositional behavior (overt, non-destructive: e.g. disobedient, doing things own way), status offences (covert, nondestructive: e.g. running away, truancy, substance abuse), and property violations (covert, destructive: e.g. lying or deceiving, selling drugs, vandalism) (Frick et al. 1993). Subsequently, a distinction was made in two groups labeled early-onset (EO) and adolescent-onset (AO). The EO group will most likely develop as a LCP group and the AO group as an $\mathrm{AL}$ group. Patients with disruptive behavior starting prior to age 12 were considered members of the EO group and those whose disruptive behavior started from age 12 on were members of the AO group (De Boer et al. 2007, 2011). In the sample, both EO $(n=134,66 \%)$ and AO $(n=69$, $34 \%$ ) groups were found.

To describe the sample, information on current DSM diagnoses, type of referral, prior experience with institutionalized care, and penal and civil measures was collected. Penal measures comprised: "probation", "mandatory treatment order", and "conditional mandatory treatment order". Civil measures comprised "supervision order", and "involuntary commitment".

The childhood risk indicators were grouped into four categories: individual, family and context, parental, and system characteristics.

\section{Individual Child Characteristics}

Information on gender, IQ (70,9\% had an IQ score measured by former institutions - WAIS: $48.6 \%$; WISC-R: $18.5 \%$; Raven: $6.9 \%$; or other measures: $36.0 \%$ ), school achievement (grade retention in primary school, and age at grade retention), and the presence of impulsive behavior and/or concentration problems was collected. The latter 
was considered present when professional help was sought because of this behavior.

\section{Family and Context Characteristics}

Information on single parenthood at birth, parent's divorce (birth-age 11), the number of changes in caregiver or changes of home environment, and maltreatment was collected. Maltreatment was divided into whether or not patients had been either physically or sexually abused.

\section{Parental Characteristics}

Information on mental health care received by at least one parent, and parental conviction(s) for crimes was collected. Parents occupational level was coded into five categories (no occupation, housekeeper, without work or unfit for work; occupation without qualification; low vocational occupation; intermediate vocational occupation; high vocational or academic occupation) and subsequently, the highest level of occupation of the parents was determined, indicating social economic status (SES). Next to occupational level we asked for the mother's employment status.

\section{System Characteristics}

System characteristics included placement outside of the home before age 12 (yes/no). Also, when relevant, the age at court custody (placement outside of the home) was recorded.

\section{Statistical Analysis}

All analyses were performed using the Statistical Package for the Social Sciences, version 17.0 (SPSS 2008). As all of the characteristics were risk indicators for onset of disruptive behavior at a young age, it was expected that they would be more present in the EO group than in the AO group, and we tested one-sided for differences. Although many childhood factors that were associated with LCP antisocial behavior seem to apply to females as well, there are indications that gender differences exist (e.g. Barnes and Beaver 2010; Eme 2007; Odgers et al. 2008). For this reason we checked for gender specificity of the characteristics. First, with chi-square tests (categorical variables) or student $t$-tests (continuous variables), the EO group was compared with the AO group. A level of significance of $p<.003$ (Bonferroni correction) was chosen to account for the number of characteristics tested. Second, in a logistic regression analysis (dependent $E O$ vs $A O)$, all characteristics were included that differed significantly $(p<.05)$ between EO and AO groups as independent variables, as well as sex. We tested for sex specific characteristics by including interaction terms with sex. Interactions with a $p$-level of $<.10$ were included in the model. The Nagelkerke $R$-square of the model was used as measure for effect size.

\section{Results}

Table 1 describes the patients included in the study. The sample was comprised of 48 female and 155 male patients with a mean age of 17.7 years. Although the level of intelligence (mostly measured at the institutions that requested the admission) of the sample was approximately average, the educational attainment was relatively low. Over $20 \%$ of the sample had a penal measure and approximately $50 \%$ had a civil measure. Some of these individuals had a civil measure and a penal measure. In addition to their psychiatric problems, all patients in the sample displayed severe disruptive behavior.

Table 2 shows the characteristics by EO and AO classification. Males were overrepresented in the EO group (82\% vs $18 \%$ females) and in the AO group (65\% vs $35 \%$ females). Table 2 shows that $\mathrm{EO}$ and $\mathrm{AO}$ groups differed on individual characteristics (in occurrence and age at grade retention in primary school, and in impulsive behavior), family and context characteristics (parental divorce (before child age 11), the number of changes in home environment, and physical abuse), parental characteristics (employment of the mother), and system characteristics (age at first placement outside of the home). The EO and AO groups did not differ on IQ, single parent at birth, sexual abuse, mental health care received by at least one of the parents, parental conviction, or SES.

\section{Sex}

When subsequently males and females of the EO group were compared, two differences in childhood characteristics were found: compared with EO males significantly more EO females had a parent who had been convicted of a crime (41\% versus $12 \%, p=.014)$ and significantly $(p<.0001)$ more females $(63 \%)$ had been sexually abused compared with males $(11 \%)$. This was also found for the AO group (65\% females, $16 \%$ males, $p=.001$ ).

\section{Logistic Regression}

The significant characteristics of Table 2 were entered into a logistic regression equation. The logistic regression analysis was performed to test the predictive value of the variables on (the dichotomous dependent variable) EO disruptive behavior. No significant differences between males and females were found after testing for interaction effects. 
Table 1 Characteristics of the sample
${ }^{\mathrm{a}} \mathrm{N}$ Number of patients for whom information about the characteristic was available

\begin{tabular}{|c|c|c|c|}
\hline $\begin{array}{l}N=203 \\
\text { Characteristic }\end{array}$ & $N^{\mathrm{a}}$ & $N$ mean & $(\%)(\mathrm{SD})$ \\
\hline Sex (male) & 203 & 155 & $(76.4 \%)$ \\
\hline Age (years) & 203 & 17.7 & $(1.2)$ \\
\hline Ethnicity Dutch & 203 & 148 & $(72.9 \%)$ \\
\hline Educational level & 198 & & \\
\hline Not attending school & & 32 & $(16.2 \%)$ \\
\hline Special education & & 18 & $(9.1 \%)$ \\
\hline Pre-vocational or junior general secondary education & & 125 & $(63.1 \%)$ \\
\hline Senior general secondary or pre-university education & & 23 & $(11.6 \%)$ \\
\hline Referral & 203 & & \\
\hline Youth care & & 92 & $(45.3 \%)$ \\
\hline Youth mental health care & & 76 & $(37.4 \%)$ \\
\hline Judicial institutions & & 35 & $(17.2 \%)$ \\
\hline Penal measure & 203 & 43 & $(21.2 \%)$ \\
\hline Civil measure & 203 & 102 & $(50.2 \%)$ \\
\hline Penal and civil measure & 203 & 11 & $(5.4 \%)$ \\
\hline Number of DSM diagnoses (Axis I) & 197 & 2.7 & $(1.2)$ \\
\hline DSM diagnoses (Axis I) & 197 & & \\
\hline Conduct disorder & & 79 & $(40.1 \%)$ \\
\hline Oppositional defiant disorder & & 55 & $(27.9 \%)$ \\
\hline Schizophrenia and related disorders & & 45 & $(22.8 \%)$ \\
\hline Mood disorder & & 34 & $(17.3 \%)$ \\
\hline Autism spectrum disorder & & 33 & $(16.8 \%)$ \\
\hline Attention-deficit/hyperactivity disorder (ADHD) & & 31 & $(15.7 \%)$ \\
\hline Anxiety disorder & & 21 & $(10.7 \%)$ \\
\hline Personality disorders (NOS and cluster B) & 198 & & \\
\hline Diagnosed & & 57 & $(28.8 \%)$ \\
\hline Suspected & & 102 & $(51.5 \%)$ \\
\hline Institutionalized care (prior to De Fjord) & 202 & & \\
\hline Yes & & 197 & $(97.5 \%)$ \\
\hline Former admissions & & 2.9 & $(2.0)$ \\
\hline Onset of disruptive behavior & 203 & & \\
\hline Early-onset $(<12$ years $)$ & & 134 & $(66.0 \%)$ \\
\hline Adolescent-onset ( $>11$ years) & & 69 & $(34.0 \%)$ \\
\hline
\end{tabular}

The first model shows the bivariate odds ratios. Each of the characteristics significantly predicted membership of the EO group, except for age at placement outside of the home. Odds ratios ranged from 1.14 (number of changes in the home environment) to 9.80 (impulsive behavior), with effect sizes ranging from 0.03 to 0.26 . The multivariate model showed three significant independent predictors of EOmembership: grade retention, impulsive behavior and physical abuse (Table 3 ). The model was statistically significant $\left(X^{2}(7, \mathrm{~N}=98)=29.72, p<.0001\right)$, indicating that the model was able to distinguish the patients with EO from those with AO disruptive behavior. The model as a whole explained $36 \%$ (Nagelkerke R square) of the variance in onset, and correctly identified $75.5 \%$ of cases.

\section{Discussion}

In previous research, in our clinical sample of inpatient adolescents with disruptive behavior and psychiatric disorders, we were able to make the distinction in EO and AO based on retrospective data (De Boer et al. 2007, 2011). The main goal of this paper was to identify factors that diagnosticians can use to differentiate between the subtypes EO and AO disruptive behavior in a clinical setting. This was done to help clinicians identify characteristics relevant to the choice of treatment for each group. Because of this practical purpose, we looked for characteristics that may easily be available in routine clinical practice. 
Table 2 Childhood characteristics by onset of disruptive behaviors and by gender $(n=203)$

\begin{tabular}{|c|c|c|c|c|c|c|}
\hline & $\mathrm{N}^{\mathrm{a}}$ & $\begin{array}{l}\mathrm{EO} O(n=110) \\
n(\%) / \mathrm{M}(\mathrm{SD})\end{array}$ & $\begin{array}{l}\mathrm{AO} \delta(n=45) \\
n(\%) / \mathrm{M}(\mathrm{SD})\end{array}$ & $\begin{array}{l}\mathrm{EO}+(n=24) \\
n(\%) / \mathrm{M}(\mathrm{SD})\end{array}$ & $\begin{array}{l}\mathrm{AO}+(n=24) \\
n(\%) / \mathrm{M}(\mathrm{SD})\end{array}$ & $\begin{array}{l}\text { EO versus } \mathrm{AO} \\
p \text {-value }\end{array}$ \\
\hline \multicolumn{7}{|l|}{ Individual } \\
\hline Intellectual ability (IQ) & 135 & $99.16(12.97)$ & $97.94(12.51)$ & $98.17(11.93)$ & $98.36(15.13)$ & 0.344 \\
\hline Grade retention in primary school & 146 & $20(26.7 \%)$ & $4(12.1 \%)$ & $5(27.8 \%)$ & $2(10.0 \%)$ & $0.023 *$ \\
\hline Age at grade retention & 72 & $8.85(3.83)$ & $10.80(2.65)$ & $8.67(3.80)$ & $10.33(15.13)$ & $0.004 *$ \\
\hline Impulsive behavior & 177 & $57(59.4 \%)$ & $6(14.3 \%)$ & $9(42.9 \%)$ & $1(5.6 \%)$ & $0.000 * *$ \\
\hline \multicolumn{7}{|l|}{ Family and context } \\
\hline Single parent at birth & 195 & $9(8.4 \%)$ & $2(5.0 \%)$ & $4(16.7 \%)$ & $4(16.7 \%)$ & 0.500 \\
\hline Parents divorced (birth—age 11) & 202 & $54(49.5 \%)$ & $12(26.7 \%)$ & $16(66.7 \%)$ & $10(41.7 \%)$ & $0.004 *$ \\
\hline Number of changes in home environment & 201 & $3.58(2.52)$ & $2.49(1.92)$ & $4.46(2.83)$ & $3.83(2.94)$ & $0.022^{*}$ \\
\hline Physical abuse & 178 & $47(47.5 \%)$ & $10(25.6 \%)$ & $11(55.0 \%)$ & $7(35.0 \%)$ & $0.009^{*}$ \\
\hline Sexual abuse & 164 & $10(11.1 \%)$ & $6(15.8 \%)$ & $12(63.2 \%)$ & $11(64.7 \%)$ & 0.092 \\
\hline \multicolumn{7}{|l|}{ Parental } \\
\hline Mental healthcare parents & 124 & $35(52.2 \%)$ & $10(31.3 \%)$ & $5(45.5 \%)$ & $8(57.1 \%)$ & 0.131 \\
\hline Conviction parents & 124 & $7(11.5 \%)$ & $1(3.2 \%)$ & $7(41.2 \%)$ & $2(13.3 \%)$ & 0.065 \\
\hline Highest occupation of both parents & 177 & - & - & - & - & 0.190 \\
\hline No & & $8(8.2 \%)$ & $2(11.8 \%)$ & $5(12.2 \%)$ & $4(18.2 \%)$ & \\
\hline Without qualification & & $6(6.2 \%)$ & $0(0 \%)$ & $3(7.3 \%)$ & $4(18.2 \%)$ & \\
\hline Low qualification & & $26(26.8 \%)$ & $6(35.3 \%)$ & $9(22.0 \%)$ & $5(22.7 \%)$ & \\
\hline Intermediate qualification & & $40(41.2 \%)$ & $8(47.1 \%)$ & $19(46.3 \%)$ & $7(31.8 \%)$ & \\
\hline High qualification & & $17(17.5 \%)$ & $1(5.1 \%)$ & $15(12.2 \%)$ & $2(9.1 \%)$ & \\
\hline Working mother & 174 & $71(74.0 \%)$ & $22(55.0 \%)$ & $10(62.5 \%)$ & $11(50.0 \%)$ & $0.009^{*}$ \\
\hline \multicolumn{7}{|l|}{ System } \\
\hline Placement outside of the home $<$ age 12 & 202 & $15(13.6 \%)$ & $2(4.5 \%)$ & $6(25.0 \%)$ & $4(16.7 \%)$ & 0.129 \\
\hline Age out placement outside of the home $<$ age 12 & 27 & $5.60(3.18)$ & $9.50(0.71)$ & $4.50(2.26)$ & $7.50(3.11)$ & $0.020^{*}$ \\
\hline
\end{tabular}

$E O$ early-onset; $A O$ adolescent-onset

${ }^{a} \mathrm{~N}$ Number of patients for whom information about the characteristic was available

${ }^{*} p<.05$ (one-tailed)

$* * p<.003$ (one-tailed), significant after Bonferroni correction

Table 3 Logistic regression analysis of the associations between childhood characteristics and $\mathrm{EO}$ and $\mathrm{AO}$ disruptive behavior

Model 1: univariate; model 2: multivariate. Multivariate model: $n=98 ; E O$ early-onset; $A O$ adolescent-onset; $O R$ odds ratio; $95 \%$ CI: $95 \%$ confidence interval; R2: Nagelkerke R2

${ }^{a}$ Due to small $\mathrm{n}$ not included in the multivariate model.

${ }^{*} p<.05 * * p<.003$, significant after Bonferroni correction. Nagelkerke R2 model 2: 0.36

\begin{tabular}{|c|c|c|c|c|c|c|}
\hline & \multicolumn{3}{|c|}{ Model 1} & \multicolumn{3}{|c|}{ Model 2} \\
\hline & $\mathrm{N}$ & OR & $95 \% \mathrm{CI}$ & $\mathrm{R} 2$ & OR & $95 \% \mathrm{CI}$ \\
\hline Sex & 203 & 2.44 & $(1.26-4.75)^{*}$ & 0.05 & 1.43 & $(0.39-5.32)$ \\
\hline Grade retention in primary school & 146 & 2.88 & $(1.10-7.56)^{*}$ & 0.05 & 4.18 & $(1.12-15.68)^{*}$ \\
\hline Age at grade retention ${ }^{\mathrm{a}}$ & 72 & 0.82 & $(0.69-0.97)^{*}$ & 0.12 & & \\
\hline Impulsive behavior & 177 & 9.80 & $(4.11-23.36)^{* *}$ & 0.26 & 6.01 & $(1.91-18.91)^{* *}$ \\
\hline Parents divorced & 203 & 2.41 & $(1.31-4.43)^{*}$ & 0.06 & 1.49 & $(0.52-4.30)$ \\
\hline $\begin{array}{l}\text { Number of changes in the } \\
\text { home environment }\end{array}$ & 201 & 1.14 & $(1.00-1.29)^{*}$ & 0.03 & 1.01 & $(0.80-1.29)$ \\
\hline Physical abuse & 178 & 2.35 & $(1.20-4.58)^{*}$ & 0.05 & 3.64 & $(1.09-12.18)^{*}$ \\
\hline Working mother & 174 & 2.30 & $(1.20-4.39)^{*}$ & 0.05 & 2.29 & $(0.76-6.88)$ \\
\hline $\begin{array}{l}\text { Age placement outside of the } \\
\text { home }<\text { age } 12^{\mathrm{a}}\end{array}$ & 27 & 0.68 & $(0.45-1.01)$ & 0.25 & & \\
\hline
\end{tabular}


As expected, the EO group showed higher levels of risk in childhood, compared to the AO group, including characteristics indicating inherited or acquired neuropsychological deficits and environmental risk factors (i.e. mean age at grade retention, grade retention in primary school, and prevalence of impulsive behavior). Besides, the $\mathrm{EO}$ and $\mathrm{AO}$ groups differed significantly on many of the other childhood risk factors (the number of changes in home environment, parental divorce (before age 11 years), physical abuse, employment of the mother, and mean age at placement outside of the home). Logistic regression yielded grade retention in primary school, impulsive behavior and physical abuse to be significantly correlated to EO disruptive behavior.

Differences in IQ were not found, but youngsters with very low cognitive ability were not included in this study because they were not eligible for treatment at De Fjord. Furthermore, the $\mathrm{EO}$ and $\mathrm{AO}$ groups did not differ on single parent at birth, sexual abuse, mental health care received by at least one of the parents, parental conviction, or SES.

It is important to note that early onset (and probably life course persistence) of disruptive behavior does occur in females. Females with EO disruptive behavior resembled their male counterparts to a great extend, they only differed on two characteristics. Compared with males of the EO group, more females with EO disruptive behavior had a parent who had been convicted of a crime. Sexual abuse was much more prevalent in females than in males, but this was found for both $\mathrm{EO}$ and $\mathrm{AO}$ groups, indicating that it was not related to the age onset of disruptive behavior. When tested for interaction effects, no significant sex differences were found. The number of girls in our sample, and the selection of characteristics were limited, but our findings do not support gender differences in these characteristics in their value for signaling EO disruptive behavior in adolescents. Gender differences may be present in biological or neurodevelopmental factors involved in the development of EO disruptive behavior (Eme 2007, 2009; Kjelsberg 1999).

It has to be noted that, methodologically, our set of variables did not permit an exhaustive test of all childhood variables that have been pinpointed to be involved in the development of LCP and AL antisocial behavior (e.g. peer characteristics, biological influences or neurodevelopmental factors). Also, the variables were not gathered at fixed moments during the early life of the patients as in epidemiological studies, but obtained retrospectively after admission. Some variables may have varied over time (e.g. child abuse, mental health of parents), but we presume that they have been considerably stable. Finally, comparison of our retrospective findings with epidemiological findings must be made with caution, because some retrospective measures (e.g. psychosocial variables) have low levels of agreement with prospective measures (Henry et al. 1994). In the present study, this was partly intercepted by using multiinformant information.

Many of the factors of epidemiological research that were found to be associated with EO disruptive behavior were also found to be associated with EO disruptive behavior in a highly selective clinical sample with severe disruptive behavior and co-occurring psychiatric disorders. This suggests that the factors associated with EO disruptive behavior probably also apply to other clinical (and nonclinical) samples with less severe psychiatric disorders and disruptive behavior. More research should be conducted among clinical and non-clinical samples to confirm this generalization.

In our study, we found characteristics that distinguish patients with EO from those with AO. We identified three independent childhood characteristics that predicted membership of the early onset group: grade retention in primary school, impulsive behavior and being physically abused. Other characteristics partly overlap in their ability to identify EO disruptive behavior. As these characteristics are not systematically collected in clinical practice, clinicians should attempt to collect information on as many as possible. The chance that the adolescent has EO disruptive behavior strongly increases in the presence of one or more of these characteristics. Because the characteristics are reasonably easy to identify, they may help clinicians to target their treatment. Adolescents with EO disruptive behavior probably benefit from interventions aimed at personality traits (psychopathic traits, impulsivity, hostility, alienation, and callousness), developing social skills (unless the individual has callous, unemotional psychopathic personality traits), aggression regulation, and education. Whereas adolescents with AO disruptive behavior probably benefit from interventions that prevent truancy or dropout from school, assertiveness therapy, or interventions that help to prevent (further) delinquent behavior.

In conclusion, in routine clinical practice information should be collected on early impulsive behavior, grade retention in primary school, and physical abuse, as this background of adolescents with severe disruptive behavior can help distinguish adolescents with early onset from those with adolescent onset disruptive behavior.

Acknowledgments The authors gratefully acknowledge Zita Haijer, manager of De Fjord, for enabling the study, the inpatients who participated, the staff members (in particular Martine van der Laan, Peter van der Sanden, Joes Hagendoorn, Farha Moussa, Petra Bakarbessy, Karolina van Iersel, Marrit Sirre) for their contribution and interest, Marike Bruinsma, who started and conducted the study in the first 5 years (1995-2000), Jos Leenes and Amos Daal for providing the essential literature, and Mathijs Deen for statistical assistance. We also wish to thank Maaike de van der Schueren for revision of the text and De Jutters, explicitly Nico Bouman, for granting dispensation to work on the paper. 
Open Access This article is distributed under the terms of the Creative Commons Attribution License which permits any use, distribution, and reproduction in any medium, provided the original author(s) and the source are credited.

\section{References}

Aguilar, B., Sroufe, L.A., Egeland, B., \& Carlson, E. (2000). Distinguishing the early-onset/persistent and adolescence-onset antisocial behavior types: From birth to 16 years. Development and Psychopathology, 12(2), 109-132.

Barnes, J., \& Beaver, K. (2010). An empirical examination of adolescence-limited offending: a direct test of Moffitt's maturity gap thesis. Journal of Criminal Justice, 38(6), 1176-1185.

Chung, I., Hill, K., Hawkins, J., Gilchrist, L., \& Nagin, D. (2002). Childhood predictors of offence trajectories. Journal of Research in Crime and Delinquency, 39, 60-90.

Dean, C.W., Brame, R., \& Piquero, A.R. (1996). Criminal propensities, discrete groups of offenders, and persistence in crime. Criminology, 34(4), 547-574.

De Boer, S., Verheij, F., \& Donker, M. (2007). Wat hebben Jeugdgezondheidszorgdossiers voor ons te verbergen? Een onderzoek naar voortekenen van latere gedragsproblemen. [What do youth health care files have to hide from us? A study into signs of later behavioral problems]. Maandblad Geestelijke Volksgezondheid, 62(7/8), 640-649.

De Boer, S., Boon, A., Verheij, F., \& Donker, M. (2011). Age of onset of conduct problems in youths with psychiatric disorders and severe disruptive behavior. Manuscript submitted for publication.

Eme, R. (2007). Sex differences in child-onset, life-course-persistent conduct disorder. A review of biological influences. Clinical Psychology Review, 27(5), 607-627.

Eme, R. (2009). Male life-course persistent antisocial behavior: a review of neurodevelopmental factors. Aggression and Violent Behavior, 14 (5), 348-358.

Fergusson, D., Horwood, L., \& Nagin, D. (2000). Offending trajectories in a New Zealand birth cohort. Criminology, 38, $525-552$.

Fontaine, N., Carbonneau, R., Vitaro, F., Barker, E., \& Tremblay, R. (2009). Research review: a critical review of studies on the developmental trajectories of antisocial behavior in females. Journal of Child Psychology and Psychiatry, 50(4), 363-385.

Frick, P., Lahey, B., Loeber, R., Tannenbaum, L., Van Horn, Y., Christ, M., et al. (1993). Oppositional defiant disorder and conduct disorder: a meta-analytic review of factor analyses and cross-validation in a clinic sample. Clinical Psychology Review, 13(4), 319-340.

Henry, B., Moffitt, T., Caspi, A., Langley, J., \& Silva, P. (1994). On the "remembrance of things past": a longitudinal evaluation of the retrospective method. Psychological Assessment, 6(2), 92-101.

Kjelsberg, E. (1999). Adolescence-limited versus life-course-persistent criminal behaviour in adolescent psychiatric inpatients. European Child \& Adolescent Psychiatry, 8(4), 276-282.

Moffitt, T. (1993). Adolescence-limited and life-course-persistent antisocial behavior: a developmental taxonomy. Psychological Review, 100, 674-701.
Moffitt, T. (2003). Life-course-persistent and adolescence-limited antisocial behavior: A 10-year research review and a research agenda. In B. Lahey, T. Moffitt, \& A. Caspi (Eds.), Causes of conduct disorder and juvenile delinquency (pp. 49-75). New York: The Guilford Press.

Moffitt, T., \& Caspi, A. (2001). Childhood predictors differentiate lifecourse persistent and adolescence-limited antisocial pathways among males and females. Development and Psychopathology, 13(02), 355-375.

Moffitt, T., Lynam, D., \& Silva, P. (1994). Neuropsychological tests predicting persistent male delinquency. Criminology, 32, 277300 .

Moffitt, T., Caspi, A., Dickson, N., Silva, P., \& Stanton, W. (1996). Childhood-onset versus adolescent-onset antisocial conduct problems in males: natural history from ages 3 to 18 years. Development and Psychopathology, 8, 399-424.

Moffitt, T., Caspi, A., Harrington, H., \& Milne, B. (2002). Males on the life-course-persistent and adolescence-limited antisocial pathways: follow-up at age 26 years. Development and Psychopathology, 14 (01), 179-207.

Moffitt, T., Arseneault, L., Jaffee, S., Kim-Cohen, J., Koenen, K., Odgers, C., et al. (2008). Research Review: DSM-V conduct disorder: research needs for an evidence base. Journal of Child Psychology and Psychiatry, 49(1), 3-33.

Nagin, D., \& Farrington, D. (1992). The onset and persistence of offending. Criminology, 30, 501-523.

Nagin, D., \& Tremblay, R. (2001). Parental and early childhood predictors of persistent physical aggression in boys from kindergarten to high school. Archives of General Psychiatry, 58, 389-394.

Odgers, C., Moffitt, T., Broadbent, J., Dickson, N., Hancox, R., Harrington, H., et al. (2008). Female and male antisocial trajectories: from childhood origins to adult outcomes. Development and Psychopathology, 20(02), 673-716.

Patterson, G., Forgatch, M., Yoerger, K., \& Stoolmiller, M. (1998). Variables that initiate and maintain an early-onset trajectory for juvenile offending. Development and Psychopathology, 10(03), $531-547$.

Shaw, D.S., Owens, E.B., Vondra, I.J., Keenan, K. \& Winslow, E.B. (1996). Early risk factors and pathways in the development of early disruptive behavior problems. Development and Psychopathology, $8,679-699$.

SPSS. (2008). SPSS 17.0 family.

Tibbetts, S., \& Piquero, A. (1999). The influence of gender, low birth weight, and disadvantaged environment in predicting early onset of offending: a test of Moffitt's interactional hypothesis. Criminology, 37(4), 843-878.

Vaughn, M., DeLisi, M., Gunter, T., Fu, Q., Beaver, K., Perron, B., et al. (2011). The severe $5 \%$ : a latent class analysis of the externalizing behavior spectrum in the United States. Journal of Criminal Justice, 39, 75-80.

Veenstra, R., Lindenberg, S., Verhulst, F., \& Ormel, J. (2009). Childhood-limited versus persistent antisocial behavior. Why do some recover and others do not? The TRAILS study. Journal of Early Adolescence, 29(5), 718-742.

Wiesner, M., \& Capaldi, D. (2003). Relations of childhood and adolescent factors to offending trajectories of young men. Journal of Research in Crime and Delinquency, 40, 231-262. 